\title{
Note
}

\section{Diet of Grey Wolves (Canis lupus) During Calving in a Moose- Caribou System in Northern Ontario}

\author{
Rob Found ${ }^{1,3,4}$, Ashley A. D. McLaren ${ }^{1}$, Arthur R. Rodgers ${ }^{2}$, and Brent R. Patterson ${ }^{1}$
}

${ }^{1}$ Ontario Ministry of Natural Resources and Forestry, Wildlife Research and Monitoring Section, Trent University, DNA Building, 2140 East Bank Drive, Peterborough, Ontario K9J 7B8 Canada

${ }^{2}$ Ontario Ministry of Natural Resources and Forestry, Centre for Northern Forest Ecosystem Research, 103 - 421 James Street South, Thunder Bay, Ontario P7E 2V6 Canada

${ }^{3}$ Current address: Parks Canada, Elk Island National Park, 1-54401, R.R. 203, Fort Saskatchewan, Alberta T8L 0V3 Canada

${ }^{4}$ Corresponding author: robert.found@pc.gc.ca

Found, Rob, Ashley A. D. McLaren, Arthur R. Rodgers, and Brent R. Patterson. 2017. Diet of Grey Wolves (Canis lupus) during calving in a Moose-Caribou system in northern Ontario. Canadian Field-Naturalist 131(3): 215-220. https://doi.org $/ 10.22621 /$ cfn.v131i3.1822

Grey Wolves (Canis lupus) are a leading proximate cause of declining populations of Woodland Caribou (Rangifer tarandus), a threatened species. Although predation on adult caribou has been well documented, less is known about predation on neonatal calves. We used scat analysis to examine the diet of wolves in an area of Ontario overlapping the receding southern limit of caribou occurrence. Wolves consumed mostly Moose (Alces americanus; 82.7\%), followed by American Beaver (Castor canadensis; $10.9 \%$ ), caribou (3.1\%), and Snowshoe Hare (Lepus americanus; $1.5 \%$ ). This low use of caribou is consistent with other evidence suggesting that caribou are a minor dietary component of wolves in this system; however, because most caribou consumption consists of calves, the impact on this slowly reproducing species may still be significant.

Key Words: Grey Wolf; Canis lupus; canids; Woodland Caribou; Rangifer tarandus; Moose; Alces americanus; American Beaver; Castor canadensis; diet; scat; predation; human disturbance; prey selection; northern Ontario

\section{Introduction}

Grey Wolves (Canis lupus) are a proximate cause of declining populations of Woodland Caribou (Rangifer tarandus) across their shared ranges (Festa-Bianchet et al. 2011). The ultimate cause may be anthropogenic disturbance, seen as the proliferation of roads and other linear features and expansion of industrial forestry (Dyer et al. 2001). These landscape modifications can improve habitat structure for Moose (Alces americanus; Schneider and Wasel 2000; Bjorneraas et al. 2011) and wolves (Dyer et al. 2001; Apps and McLellan 2006) leading to increases in densities of both species (Seip 1992; Wittmer et al. 2007). Although wolves may target Moose as their primary prey, greater wolf density can lead to an increased frequency of incidental encounters with secondary or tertiary prey (Bergerud 1988; Seip 1992; James et al. 2004). The impact of this incidental predation may be negligible when the prey in question is highly productive, such as American Beaver (Castor canadensis) or Snowshoe Hare (Lepus americanus), but it can be serious for caribou, which occur in naturally low densities, reproduce slowly, and whose inherent sensitivity to human disturbance increasingly limits their distribution (Cumming et al. 1996; Wittmer et al. 2007).

The potential use of caribou by wolves in northern Ontario, Canada, is of particular interest because the Woodland Caribou Boreal population is listed as "threatened" both nationally (SARA Registry 2014) and provincially (COSSARO 2007). The southernmost range of Woodland Caribou in Ontario has been retreating northward, and now approximates the northern extent of commercial forestry in the province (Schaefer 2003; Vors et al. 2007). As in other jurisdictions, human disturbance and commercial forestry activities in this mixed coniferous-deciduous forest has changed the seral composition and forest structure (Bowman et al. 2010) and the area now supports moderate densities of Moose and wolves, but low caribou density (Avgar et al. 2015).

Our objective was to determine the diversity and proportions of prey selected by wolves during the ungulate calving season in a region of Ontario where Moose, beaver, and caribou were expected to be the major prey. In particular, we wished to document the extent of wolf consumption of both adult and neonatal caribou and Moose and explore the potential for wolf predation to be a limiting factor for caribou in this area. Because of their relatively high density, we expected Moose would be the main prey item found in wolf scats. However, because of the density and prevalence of wolves across the study area, we expected caribou and beaver to be important alternative prey.

\section{Methods}

Our study focused on the Ogoki-Nakina forest in Ontario (centroid: $87.7^{\circ} \mathrm{W}, 50.5^{\circ} \mathrm{N}$ ). Human disturbance in this area is high, with $41 \mathrm{~km}$ of road per $100 \mathrm{~km}^{2}$ and commercial logging across $28 \%$ of the region (Thompson et al. 2014). The area now supports moderate densities of Moose $\left(11.8 / 100 \mathrm{~km}^{2}\right)$ and wolves $(0.67 / 100$ $\mathrm{km}^{2}$; Kittle et al. 2015) and a low density of caribou (minimum $0.50 / 100 \mathrm{~km}^{2}$; MNRF 2014). The region is 
also populated by Snowshoe Hare, beaver, and other small mammals representing potential prey items for wolves.

We determined the diversity and relative proportion of prey items in wolf diets by examining scat samples and calculating percentage biomass of prey consumed (Floyd et al. 1978; Ciucci et al. 1996; Klare et al. 2011). We collected scats opportunistically along roads and trails between 23 May and 19 June $2012(n=31)$ and $2013(n=70)$. Scats were also collected from the territories of up to 13 wolf packs using the study area, but, because road and trail access was not equal across the entire study area, we opportunistically encountered more scats in certain areas. We minimized pseudo-replication by using both spatial and temporal separation of sampling events to reduce the likelihood of collecting multiple scats from the same individual. We analyzed only the first scat found at any location where multiple scats were deposited on the same day. Scats were located while driving along multiple roads and walking multiple trails each day and collected on 16 days. Of seven scats ultimately found to contain caribou, six were collected on different days, and all seven were also from different locations. We pooled the results from both years into a single data set $(n=101)$, to exceed the minimum $(n=59)$ recommended by Trites and Joy (2005) for inferring population-wide dietary trends.

We rinsed boiled scats in water for 2-3 minutes and air-dried them overnight. Dried, undigested matter was spread onto a grid sheet divided into 20 cells, which allowed estimates of relative proportions of diet components (i.e., coverage of one cell $=5 \%$ of scat). We expected wolves to feed mostly on mammalian prey, which are best identified using hairs found in scats (Lockie 1959; Korschgen 1980). We identified hairs visually, either unaided or microscopically, from either cuticular impression mounts or whole mounts, using a reference guide for mammalian hair in Ontario (Adorjan and Kolenosky 1969). This guide also allowed us to differentiate between calves and adults of ungulate species.

To quantify dietary variation, we recorded the frequency of occurrence of each dietary item and the percentage it contributed to total scat volume. Because increasing prey body size results in an increasing ratio of digestible to indigestible mass, the proportion of prey in scat is not representative of the relative amount of prey originally consumed (Klare et al. 2011). Smaller prey tend to be over-represented in scats based on volume, particularly in diets of predators whose main prey include a mix of large and small prey. Using controlled feeding trials on wolves, Weaver (1993) derived a formula to correct biases in the diets of wolves whose main prey include both very large (e.g., Moose) and smaller prey (e.g., beaver). We used that equation mass of prey per collectable scat $=0.439+(0.008)^{*}$ (body mass of prey) - to correct for biases in prey body size and convert percentage scat volume to per- centage biomass in the diet. Because the formula was validated in wolf diets containing prey ranging in size from Snowshoe Hare to Moose, we calculated percentage biomass only for Moose, caribou, beaver, and hare. As data for the Weaver formula, we used the following literature-derived average body masses: Moose adult $475 \mathrm{~kg}$ (Quinn and Aho 1989) and calf $24 \mathrm{~kg}$ (at 3 weeks; Addison et al. 1994); caribou adult $130 \mathrm{~kg}$ (Kelsall 1984) and calf $10 \mathrm{~kg}$ (at 3 weeks; Kojola 1993); beaver, $18 \mathrm{~kg}$ (Hoover and Clarke 1972); and Snowshoe Hare $1.5 \mathrm{~kg}$ (Bennett et al. 2005). We calculated separate percentage biomasses for ungulate adults and calves then combined them to derive the overall percentage biomass for each ungulate species.

\section{Results}

Wolves consumed 12 identifiable dietary items, of which eight were animal and four vegetable. All scats contained some animal matter, while $38.6 \%$ contained vegetable matter. The most frequently occurring item was Moose, which was found in $51.5 \%$ of all scats, followed by beaver $(38.6 \%)$, grasses $(18.8 \%)$, Snowshoe Hare $(9.9 \%)$, and caribou (6.9\%; Figure 1). By proportion of total scat volume, Moose (44.9\%) and beaver (34.4\%) remained the top two dietary items, followed by caribou (6.5\%), then Snowshoe Hare (6.2\%). By volume, all other dietary items contributed less than $1.5 \%$ each to the total wolf diet. Total grass consumption by volume was only $1.3 \%$, making it disproportionately frequent in scats compared to the relatively small amount of grass present. Diet items whose frequency of occurrence is relatively larger than their percentage volume may be important only in low quantities, but may also represent smaller units of prey representing incomplete meals for wolves. Black Bear (Ursus americanus) made up 1\% of total scat volume, but this was the result of a single scat containing the only occurrence of bear. Just over half $(50.5 \%)$ of all scats contained a single dietary item, $31.7 \%$ contained two dietary items, $14.9 \%$ contained three dietary items, and just $2.0 \%$ and $1.0 \%$ contained four and five dietary items, respectively.

We were able to differentiate between hairs of ungulate adults and calves and found that 15 of 52 occurrences of Moose in scats were calves $(30.7 \%$ of total Moose biomass) and four of seven occurrences of caribou were calves (69.5\% of total caribou biomass). Based on these biomass values, wolves consumed mostly Moose ( $82.7 \%)$, followed by beaver $(10.9 \%)$, caribou (3.1\%), and Snowshoe Hare (1.5\%; Figure 2). By biomass, only $6.0 \%$ of total Moose consumption consisted of calves, but $45.2 \%$ of caribou consumption consisted of calves.

\section{Discussion}

Moose were the dominant item in the spring diet of wolves in our study area, while smaller proportions of caribou $(3.1 \%)$ and beaver $(10.9 \%)$ indicated that they 


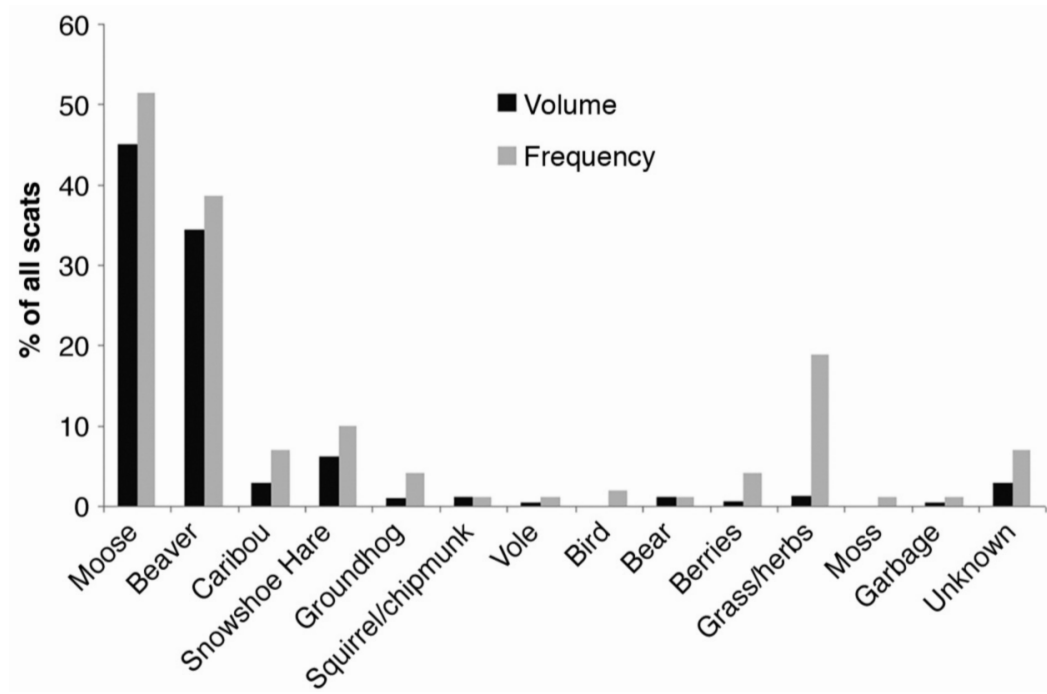

FigURE 1. Volume and frequency of occurrence of various prey items in Grey Wolf (Canis lupus) scats collected in northern Ontario from late May to late June, 2012 and $2013(n=101)$. Differences between frequency and volume for a prey item tell us, for example, that wolves eat grass often, but not much of it. Grasses are almost always part of mixedspecies scats as either a supplemental food or incidental consumption. In contrast, the biomass and frequency of caribou are similar, indicating that it is a major prey item found more often in single-prey-item scats.

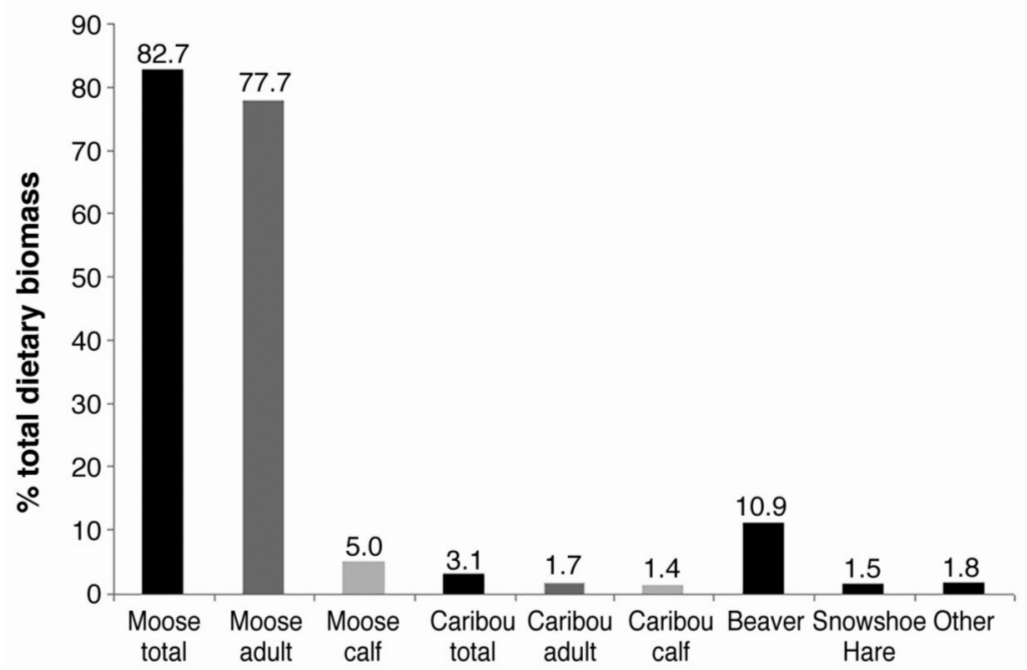

FIGURE 2. Proportion of various prey species consumed by Grey Wolves (Canis lupus) in northern Ontario from late May to late June, 2012 and 2013, based on calculated percentage of biomass in scat $(n=101)$.

were of less importance to wolves. These results are similar to those of other studies of spring-summer wolf diet results which ranked Moose as the main diet item, followed distantly by beaver and caribou as important alternate food sources (May-June, Ballard et al. 1987; May-October, Tremblay et al. 2001; Latham et al. 2011).

Selection of ungulates by wolves may correspond directly to the availability of that prey (Spaulding et al. 1998), but it may also be a function of increased effort and risk to wolves from hunting larger prey (Smith et al. 2000). For example, in Alaska, caribou remained the primary prey even when Moose were twice as abundant (Dale et al. 1993). A study of wolf predation during years of changing deer density in Quebec found that Moose was the primary spring-summer prey, but deer was the primary winter prey even when they were at a much lower density than Moose (Potvin et al. 1988). In contrast, in our system, wolves favoured the largest ungulate available, perhaps because the ease of finding abundant Moose offset the extra effort and risk required to kill them. 
Although we expected the timing of our study to be optimal for detecting consumption of ungulate calves, it may also have been optimal for predation on beaver. We found a relatively large amount of beaver in wolf diets, possibly because our study period immediately followed ice-out for beavers (when surface ice on ponds and rivers thaws enough to allow beavers to resume movement between water and land), which occurs in late April through May. Beaver are nutrition stressed at this time, which drives increased foraging activity both in and out of the water and, subsequently, increases their risk of predation (Kallemeyn et al. 2003). An example of this was found in northeast Alberta, where despite the availability of deer, Moose, and caribou calves, beaver were the primary prey of wolves during May and June (Latham et al. 2013). Wolves may also have been targeting beavers during our study.

Half of all the wolf scats we examined contained only one diet item; this is expected in diets dominated by large prey, which typically provide complete or even multiple meals for multiple wolves. Although nearly half the scats we examined contained multiple prey items, we expect that this spring-early summer prey diversity would decline with the onset of winter, with reduced availability of vegetative matter and access to prey such as beavers. Among scats containing Snowshoe Hare, all but two also contained Moose or beaver, suggesting that wolves did not rely on such small prey, but likely ate them opportunistically while targeting larger prey. Opportunism was also evident in the presence of anthropogenic garbage in one scat and Black Bear hair in another single scat. Conversely, grasses were found in low volumes (1.3\%) but high frequency $(18 \%)$, suggesting that they are an important dietary supplement (Ciucci et al. 1996). Consumption of grasses and herbs by canids is intentional and likely a way to acquire vitamins or self-treat for intestinal parasites (Mech 1970).

Moose calves made up nearly a third of all Moose biomass consumed by wolves during our study, but caribou calves made up over two-thirds of all caribou biomass consumed, which is four times what would be expected based on estimated caribou density compared with Moose density in the area. Our study period overlapped ungulate calving season, when the young are most vulnerable and generally targeted by predators (Pimlott 1974; Fritts and Mech 1981), but our results suggest that caribou calves, in particular, may have been targeted by wolves at this time. Latham et al. (2013) found low predation rates by wolves on caribou calves, but also greater selection by wolves of cariboupreferred habitats during calving season, which also suggested caribou calves were being specifically targetted. Results from scats collected in Alaska during May-June from wolf territories with low caribou and Moose densities showed $89.5 \%$ of total Moose consumption consisted of Moose calves, but only $15 \%$ of total caribou consumption consisted of caribou calves
(Ballard et al. 1987); these results were based on 40 scats collected from a single denning site. Further compounding the risk to caribou, wolves are likely not the only predators on caribou calves, as Black Bears were common in our study area. In a similar highly managed landscape in the neighbouring province of Quebec, $57 \%$ of caribou calves were killed by Black Bears, while only $4.3 \%$ were killed by wolves (Pinard et al. 2012).

Because wolves adjust their search images and strategies to target primary prey, secondary prey are usually hunted only incidentally (Carbyn 1987). However, when landscape changes enhance habitat for primary prey and wolf populations increase in response, rates of incidental predation on secondary prey can also increase, and mortality rates can be highest where that prey's densities are lowest (e.g., Bergerud 1988; Hayes et al. 2000; James et al. 2004).

Although caribou represented only $3.1 \%$ of the biomass consumed by wolves in early summer, given the typical low rate of increase of caribou populations, low density relative to wolf density in this system, incidental predation of caribou, and consumption of caribou calves, this may still have serious conservation implications when combined with other stressors (Wittmer et al. 2013; Beauchesne et al. 2014).

\section{Acknowledgements}

We thank the staff at the Centre for Northern Forest Ecosystem Research for logistical support in the field. Erica Newton, Jennifer Rodgers, Andrew Silver, and Scott Taylor prepared samples and analyzed the diet composition of the scats. Financial support was provided by the Forest Ecosystem Science Co-operative Inc., the Natural Sciences and Engineering Research Council, Collaborative Research and Development program, Canadian Forest Service, and the Wildlife Research and Monitoring Section and the Centre for Northern Forest Ecosystem Research of the Ontario Ministry of Natural Resources and Forestry.

\section{Literature Cited}

Addison, E. M., R. F. McLaughlin, and J. D. Broadfoot. 1994. Growth of moose calves (Alces alces americana) infested and uninfested with winter ticks (Dermacentor albipictus). Canadian Journal of Zoology 72: 1469-1476. https://doi.org/10.1139/z94-194

Adorjan, A. S., and G. B. Kolenosky. 1969. A manual for the identification of hairs of selected Ontario mammals. Research report 90. Ontario Department of Lands and Forests, Toronto, Ontario, Canada.

Apps, C. D., and B. N. McLellan. 2006. Factors influencing the dispersion and fragmentation of endangered mountain caribou populations. Biological Conservation 130: 84-97. https://doi.org/10.1016

Avgar, T., J. A. Baker, G. S. Brown, J. S. Hagens, A. M. Kittle, E. E. Mallon, M. T. McGreer, A. Mosser, S. G. Newmaster, B. R. Patterson, D. E. Reid, A. R. Rodgers, J. Shuter, G. M. Street, I. Thompson, M. J. Turetsky, P. A. Wiebe, and J. M. Fryxell. 2015. Space-use behav- 
iour of woodland caribou based on a cognitive movement model. Journal of Animal Ecology 84: 1059-1070. https: //doi.org/10.1111/1365-2656.12357

Ballard, W. B., J. S. Whitman, and C. L. Gardner. 1987. Ecology of an exploited wolf population in south-central Alaska. Wildlife monographs 98. Wildlife Society, Bethesda, Maryland, USA.

Beauchesne, D., J. A. G. Jaeger, and M.-H. St. Laurent. 2014. Thresholds in the capacity of boreal caribou to cope with cumulative disturbances: evidence from space use patterns. Biological Conservation 172: 190-199. https:// doi.org/10.1016/j.biocon.2014.03.002

Bennett, K. E., E. M. Baggs, J. R. Finney-Crawley, and M. McGrath. 2005. An analysis of the parasites of a midwinter population of the snowshoe hare, Lepus americanus, on insular Newfoundland during a cyclical peak. Canadian Field-Naturalist 119: 323-329. https://doi.org/10.22621 /cfn.v119i3.141

Bergerud, A. T. 1988. Caribou, wolves and man. Trends in Ecology \& Evolution 3: 68-72. https://doi.org/10.1016 /0169-5347(88)90019-5

Bjørneraas, K., E. J. Solberg, I. Herfindal, B. Van Moorter, C. M. Rolandsen, J.-P. Tremblay, C. Skarpe, B.-E. Saether, R. Eriksen, and R. Astrup. 2011. Moose Alces alces habitat use at multiple temporal scales in a humanaltered landscape. Wildlife Biology 17: 44-54. https://doi .org/10.2981/10-073

Bowman, J., J. C. Ray, A. J. Magoun, D. S. Johnson, and F. N. Dawson. 2010. Roads, logging, and the large-mammal community of an eastern Canadian boreal forest. Canadian Journal of Zoology 88: 454-467. https://doi.org/10.1139 /z10-019

Carbyn, L. N. 1987. Gray wolf and red wolf. Pages 359-376 in Wild Furbearer Management and Conservation in North America. Edited by M. Novak, J. A. Baker, M. E. Obbard, and B. Malloch. Ontario Trappers Association, Toronto, Ontario, Canada.

Ciucci, P., L. Boitani, E. R. Pelliccioni, M. Rocco, and I. Guy. 1996. A comparison of scat-analysis methods to assess the diet of the wolf Canis lupus. Wildlife Biology 2: 37-48.

COSSARO (Committee on the Status of Species at Risk in Ontario). 2007. Endangered Species Act, 2007, S. O. 2007. Queen's Printer for Ontario, Toronto, Ontario, Canada.

Cumming, H. G., D. B. Beange, and G. Lavoie. 1996. Habitat partitioning between woodland caribou and moose in Ontario: the potential role of shared predation risk. Rangifer 16: 81-94. https://doi.org/10.7557/2.16.4.1224

Dale, B. W., L. G. Adams, and R. T. Bowyer. 1993. Winter wolf predation in a multiple ungulate prey system, Gates of the Arctic National Park, Alaska. Pages 223-230 in Ecology and Conservation of Wolves in a Changing World. Occasional publication 35. Edited by L. N. Carbyn, S. H. Fritts, and D. R. Seip. Canadian Circumpolar Institute, Edmonton, Alberta, Canada.

Dyer, S. J., J. P. O’Neill, S. M. Wasel, and S. Boutin. 2001 Avoidance of industrial development by woodland caribou. Journal of Wildlife Management 65: 531-542. https:// doi.org/10.2307/3803106

Festa-Bianchet, M., J. C. Ray, S. Boutin, S. D. Cote, and A. Gunn. 2011. Conservation of caribou (Rangifer tarandus) in Canada: an uncertain future. Canadian Journal of Zoology 89: 419-434. https://doi.org/10.1139/z11-025

Floyd, T. J., L. D. Mech, and P. A. Jordan.1978. Relating wolf scat contents to prey consumed. Journal of Wildlife Management 43: 528-532. https://doi.org/10.2307/3800814
Fritts, S. H., and L. D. Mech. 1981. Dynamics, movements, and feeding ecology of a newly protected wolf population in northwestern Minnesota. Wildlife monographs 80 . Wildlife Society, Bethesda, Maryland, USA.

Hayes, R. D., A. M. Baer, U. Wotschikowsky, and A. S. Harestad. 2000. Kill rate by wolves on moose in Yukon. Canadian Journal of Zoology 78: 49-59. https://doi.org/10 $.1139 / \mathrm{z} 99-187$

Hoover, W. H., and S. D. Clarke. 1972. Fiber digestion in the beaver. Journal of Nutrition 102: 9-16.

James, A. R. C., S. Boutin, D. M. Hebert, and A. B. Rippin. 2004. Spatial separation of caribou from moose and its relation to predation by wolves. Journal of Wildlife Management 68: 799-809. https://doi.org/10.2193/0022-541X (2004)068[0799:SSOCFM]2.0.CO;2

Kallemeyn, L. W., K. L. Holmberg, J. A. Perry, and B. Y. Odde. 2003. Aquatic synthesis for Voyageurs National Park. Information and technology report 2003-0001. United States Geological Survey, Reston, Virginia, USA.

Kelsall, J. P. 1984. COSEWIC status report on the woodland caribou Rangifer tarandus caribou in Canada. Committee on the Status of Endangered Wildlife in Canada. Ottawa, Ontario, Canada.

Kittle, A. M., M. Anderson, T. Avgar, J. A. Baker, G. S. Brown, J. Hagens, E. Iwachewski, S. Moffat, A. Mosser, B. R. Patterson, D. E. B. Reid, A. R. Rodgers, J. Shuter, G. M. Street, I. D. Thompson, L. M. Vander Vennen, and J. M. Fryxell. 2015. Wolves adapt territory size, not pack size to local habitat quality. Journal of Animal Ecology 84: 1177-1186. https://doi.org/10.1111/1365-2656.12 366

Klare, U., J. F. Kamler, and D. W. MacDonald. 2011. A comparison and critique of different scat-analysis methods for determining carnivore diet. Mammal Review 41: 294-312. https://doi.org/10.1111/j.1365-2907.2011.00183.x

Kojola, I. 1993. Early maternal investment and growth in reindeer. Canadian Journal of Zoology 71: 753-758. https: //doi.org/10.1139/z93-099

Korschgen L. K. 1980. Procedure for food habits analysis. Pages 113-128 in Wildlife Management Techniques Manual. Edited by S. D. Schemnitz. Wildlife Society, Bethesda, Maryland, USA.

Latham, A. D. M., M. C. Latham, M. S. Boyce, and S. Boutin. 2013. Spatial relationships of sympatric wolves (Canis lupus) and coyotes (C. latrans) with woodland caribou (Rangifer tarandus caribou) during the calving season in a human-modified boreal landscape. Wildlife Research 40: 250-260. https://doi.org/10.1071/WR12184

Latham, A. D. M., M. C. Latham, N. A. McCutchen, and S. Boutin. 2011. Invading white-tailed deer change wolfcaribou dynamics in northeastern Alberta. Journal of Wildlife Management 75: 204-212. https://doi.org/10.1002/jw mg. 28

Lockie, D. 1959. The estimation of the food of foxes. Journal of Wildlife Management 23: 224-227.

Mech, L. D. 1970. The Wolf: The Ecology and Behavior of an Endangered Species. Natural History Press, Garden City, New York, New York, USA.

MNRF (Ministry of Natural Resources and Forestry). 2014. Integrated range assessment for woodland caribou and their habitat: Nipigon range 2010. Species at Risk Branch, MNRF, Thunder Bay, Ontario, Canada.

Pimlott, D. H. 1974. The ecology of the wolf in North America. Pages 280-285 in The Wild Canids: Their Systematics, 
Behavioral Ecology and Evolution. Edited by M. W. Fox. Van Nostrand-Reeinhold, New York, New York, USA.

Pinard, V., C. Dussault, J.-P. Ouellet, D. Fortin, and R. Courtois. 2012. Calving rate, calf survival rate, and habitat selection of forest-dwelling caribou in a highly managed landscape. Journal of Wildlife Management 76: 189-199. https://doi.org/10.1002/jwmg.217

Potvin, F., H. Jolicoeur, and J. Huot. 1988. Wolf diet and prey selectivity during two periods for deer in Quebec: decline versus expansion. Canadian Journal of Zoology 66: 1274-1279. https://doi.org/10.1139/z88-186

Quinn, N. W. S., and R. W. Aho. 1989. Whole weights of moose from Algonquin Park, Ontario, Canada. Alces 25: 48-51.

SARA (Species at Risk Act) Registry. 2014. Species profile: Caribou Boreal population. Accessed 8 March 2017. http://www.sararegistry.gc.ca/species/speciesDetails_e.cfm ?sid $=636$.

Schaefer, J. A. 2003. Long-term range recession and the persistence of caribou in the taiga. Conservation Biology 17: 1435-1439. https://doi.org/10.1046/j.1523-1739.2003. 02288.x

Schneider, R. R., and S. Wasel. 2000. The effect of settlement on the density of moose in northern Alberta. Journal of Wildlife Management 64: 513-520.

Seip, D. R. 1992. Factors limiting woodland caribou populations and their interrelationships with wolves and moose in southeastern British Columbia. Canadian Journal of Zoology 70: 1494-1503. https://doi.org/10.1139/z92-206

Smith, D. W., L. D. Mech, M. Meagher, W. E. Clark, R. Jaffe, M. K. Phillips, and J. A. Mack. 2000. Wolf-bison interactions in Yellowstone National Park. Journal of Mammalogy 81: 1128-1135. https://doi.org/10.1644/1545-1542 (2000)081<1128:WBIIYN $>2.0 . C O ; 2$

Spaulding, R. L., P. R. Krausman, and W. B. Ballard. 1998. Summer diet of Gray Wolves, Canis lupus, in north- western Alaska. Canadian Field-Naturalist 112: 262-266. Accessed 23 December 2017. https://www.biodiversity library.org/item/106776\#page/274/mode/1up.

Thompson, I. D., P. A. Wiebe, E. Mallon, A. R. Rodgers, J. M. Fryxell, J. A. Baker, and D. Reid. 2014. Factors influencing the seasonal diet selection by woodland caribou (Rangifer tarandus tarandus) in boreal forests in Ontario. Canadian Journal of Zoology 93: 87-98. https://doi.org/10 $.1139 /$ cjz-2014-0140

Tremblay, J.-P., H. Jolicoeur, and R. Lemieux. 2001. Summer food habits of gray wolves in the boreal forest of the Lac Jacques-Cartier Highlands, Québec. Alces 37: 1-12.

Trites, A. W., and R. Joy. 2005. Dietary analysis from fecal samples: how many scats are enough? Journal of Mammalogy 86: 704-712. https://doi.org/10.1644/1545-1542(2005) 086[0704:DAFFSH]2.0.CO;2

Vors, L. S., J. A. Schaefer, B. A. Pond, A. R. Rodgers, and B. R. Patterson. 2007. Woodland caribou extirpation and anthropogenic landscape disturbance in Ontario. Journal of Wildlife Management 71: 1249-1256. https://doi.org/10 $.2193 / 2006-263$

Weaver, J. L. 1993. Refining the equation for interpreting prey occurence in gray wolf scats. The Journal of Wildlife Management 57: 534-538.

Wittmer, H. U., B. N. McLellan, R. Serroya, and C. D. Apps. 2007. Changes in landscape composition influence the decline of a threatened woodland caribou population. Journal of Animal Ecology 76: 568-579. https://doi.org /10.1111/j.1365-2656.2007.01220.x

Wittmer, H. U., R. Serrouya, L. M. Elbroch, and A. J. Marshall. 2013. Conservation strategies for species affected by apparent competition. Conservation Biology 27: 254-260. https://doi.org/10.1111/cobi.12005

Received 7 July 2016

Accepted 7 June 2017 